\title{
Emphysematous gastritis as a manifestation of non-occlusive mesenteric ischemia after coartectomy
}

\section{Gastritis enfisematosa como manifestación de isquemia mesentérica no oclusiva tras coartectomía}

\author{
Deyanira Quiñonez-López ${ }^{\text {* }}$, Carolina Gutiérrez-Cortés², Catalina Lince-Rivera², \\ César A. Zuluaga-Orrego ${ }^{1}$, and Edgar Giovanny-Ríos ${ }^{3}$ \\ ${ }^{1}$ Pediatric Intensive Care Unit; ${ }^{2}$ Department of Pediatrics; ${ }^{3}$ Department of Cardiovascular Surgery. Hospital Universitario San Ignacio, Cundinamarca, \\ Bogota D.C., Colombia
}

\begin{abstract}
Major interventions in cardiovascular surgery of patients with aortic pathology can result in the compromise of perfusion of organs distant from the surgery site, the gastrointestinal tract being one of the most sensitive to hemodynamic changes, especially in extreme age groups with a high risk of morbidity and mortality. The case of a young infant is reported, with a history of Turner syndrome, who is led to correction of aortic coarctation plus arch hypoplasia, presenting as a postoperative complication a picture of emphysematous gastritis with systemic compromise, a process that was favored by low cardiac output post-pump and the presence of early urosepsis, all of which was interpreted as part of the spectrum of non-occlusive mesenteric ischemia syndrome. Its early diagnosis made possible a prompt intervention consisting of parenteral nutritional support, acid brake, broad-spectrum antibiotic therapy and strict radiological follow-up, achieving complete resolution of her symptoms, without short-term complications. This case demonstrated that the identification of risk factors for splanchnic ischemia, a high clinical suspicion and careful medical management, allowed a favorable outcome for a disease with a high mortality rate and very few cases reported in the pediatric population.
\end{abstract}

Key words: Coarctation of the aorta. Emphysematous gastritis. Mesenteric ischemia. Gastric pneumatosis.

\section{Resumen}

Las intervenciones mayores en cirugía cardiovascular de pacientes con patología aórtica pueden traer como consecuencia el compromiso de la perfusión de órganos distantes al sitio de la cirugía, siendo el tracto gastrointestinal uno de los más sensibles a los cambios hemodinámicos, en especial en grupos extremos de edad con un alto riesgo de morbimortalidad. Se reporta el caso de una lactante con antecedente de síndrome de Turner, quien es llevada a corrección de coartación de aorta más hipoplasia del arco, presentando como complicación posoperatoria un cuadro de gastritis enfisematosa con compromiso sistémico, proceso que fue favorecido por bajo gasto cardiaco posterior a bomba y presencia de urosepsis tempra-

\section{Correspondencia:}

*Deyanira Quiñonez-López

E-mail: adquinonez@ husi.org.co
Date of reception: $26-04-2020$

Date of acceptance: 16-05-2020

DOI: 10.24875/ACME.M21000212
Available online: 19-07-2021 Arch Cardiol Mex (Eng). 2021;91(2):183-188 www.archivoscardiologia.com 2604-7063 / @ 2020 Instituto Nacional de Cardiología Ignacio Chávez. Published by Permanyer. This is an open access article under the CC BY-NC-ND license (http://creativecommons.org/licenses/by-nc-nd/4.0/). 
na, todo lo cual fue interpretado como parte del espectro del síndrome de isquemia mesentérica no oclusiva. Su diagnóstico precoz hizo posible una pronta intervención, consistente en soporte nutricional parenteral, freno ácido, antibioticoterapia de amplio espectro y seguimiento radiológico estricto, logrando la resolución completa de su sintomatología, sin complicaciones a corto plazo. Este caso demuestra que la identificación de factores de riesgo de isquemia esplácnica, una alta sospecha clínica y un cuidadoso manejo médico permiten un desenlace favorable para una patología con una alta tasa de mortalidad y muy pocos casos reportados en población pediátrica.

Palabras clave: Coartación de aorta. Gastritis enfisematosa. Isquemia mesentérica. Neumatosis gástrica.

\section{Introduction}

Coarctation of the aorta has a severity spectrum in which early age at presentation is closely correlated with obstruction severity and associated defects ${ }^{1}$. The most commonly described splanchnic complication after surgical correction of this pathology is post-coarctectomy syndrome, secondary to the presence of necrotizing arteritis compromising the mesenteric bed, which is related to the development of hypertension within the first 48 hours of the postoperative period. However, the opposite spectrum is described, which corresponds to non-occlusive mesenteric ischemia syndrome, and that accounts for $1-4 \%$ of total post-surgical cardiovascular complications ${ }^{1-3}$. It typically occurs in cases of severe hypotension with variable bowel involvement extent ${ }^{3}$. Within this wide range, emphysematous gastritis could be considered, which despite being a rare condition, is one of the most serious manifestations of intestinal ischemic events, with a mortality of up to $61 \%$ being described 4 .

This work presents the case of a female infant with severe aortic coarctation, who underwent total surgical correction under cardiopulmonary bypass on the second month of life. During the postoperative period, she developed low-output syndrome of multifactorial etiology, there was evidence of upper gastrointestinal bleeding with hemodynamic repercussions and radiological confirmation of emphysematous gastritis. She had an adequate response to conservative medical management, consisting of cardiorespiratory support, support with blood products, antibiotic therapy and total parenteral nutritional support. The patient underwent a slow recovery process, which allowed her transfer to the high-dependency unit and subsequent discharge without complications.

\section{Case presentation}

Female patient, born at term, 37-week Ballard score, with antenatal diagnosis of Turner syndrome $(45 \mathrm{X})$ and coarctation of aorta. At birth, echocardiography confirmed the existence of congenital heart disease of the extensive aorta coarctation type, with proximal and distal arch involvement, $2 \mathrm{~mm}$ in diameter and 14-mm coarctation segment, bivalve aortic valve, double superior vena cava system, large 5.2-mm patent ductus arteriosus with bidirectional shunt and signs of moderate pulmonary hypertension. The patient was managed since birth with preventive fasting and prostaglandin infusion. Once weight gain was achieved, at 41 days of life, she underwent surgery for extensive reconstruction of the aortic arch with distal aorta native tissue and patent ductus arteriosus closure, under cardiopulmonary bypass, with deep hypothermia at $18 \stackrel{\circ}{\mathrm{C}}$ and circulatory arrest with protective anterograde brain perfusion, with pump time of 171 minutes, clamping time of 43 minutes and 43-minute arrest time. In the immediate postoperative period, urinary tract infection by extended spectrum beta-lactamase-producing Escherichia coli was documented, with treatment with a carbapenem therefore being started. She was in a state of vasoplegic shock secondary to a post-pump inflammatory response and associated infectious condition, with multiple vasoactive support and systemic steroid being required owing to the suspicion of critically-ill patient adrenal insufficiency, as well as high-dose diuretic support infusion due to the presence of oliguria. Forty-eight hours after the surgical procedure, trophic stimulus with breast milk was started, with evidence of coffee ground vomitus and abdominal distention 24 hours later. The first radiological control showed poor gas distribution pattern, without other alterations. She remained on fasting for 3 more days and, prior to a new intestinal stimulus, an X-ray revealed the presence of gastric pneumatosis (Fig. 1). For this reason, fasting was maintained indefinitely, a silicone tube was placed to prevent gastric mucosa damage from perpetuating, and support was started with total parenteral nutrition and acid suppression with a proton pump inhibitor, with a total of four episodes of gastrointestinal coffee ground bleeding taking place despite intestinal rest. In addition to this, she had secondary anemia with hemodynamic compromise 


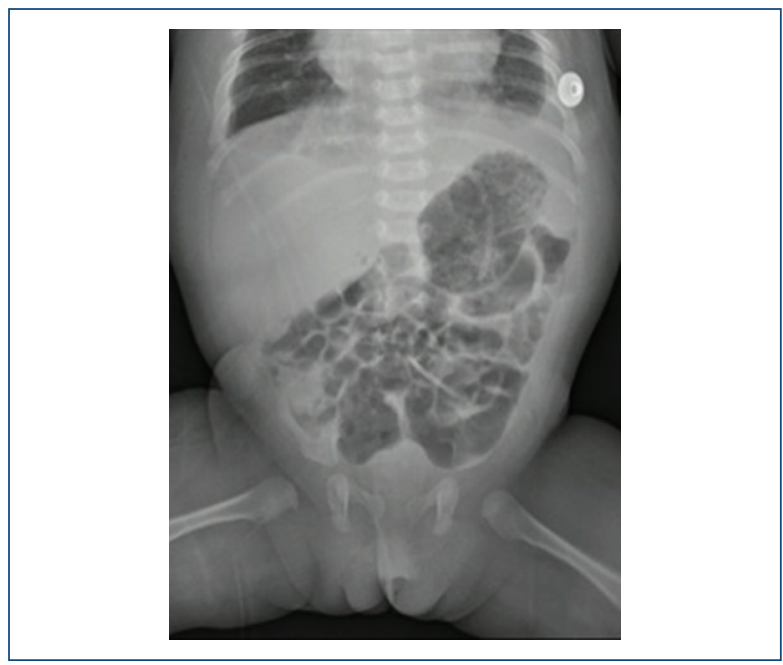

Figure 1. Gastric pneumatosis.

corresponding to a 3-g hemoglobin decrease with regard to admission levels, which required packed red blood cells transfusion. In total, two sets of blood cultures were carried out, which were negative. Abdominal ultrasound showed no alterations. In interdisciplinary management with the pediatric surgery and gastroenterology departments, carrying out daily radiological control was decided, with progressive improvement being observed (Figs. 2 and 3), and enteral nutrition was restarted with extensively hydrolyzed formula until completing 7 days from the last normal radiological control. Adequate tolerance to enteral route progression was corroborated, without new abdominal distention, vomiting or radiological deterioration events. From the cardiorespiratory point of view, vasopressor and ventilatory support successful weaning was feasible, with beta-blocker support being required given the presence of left ventricular residual concentric hypertrophy, with adequate response. Finally, she was transferred to the high-dependency unit, and subsequently she was discharged without complications.

\section{Discussion}

Numerous surgical procedures have been implemented to repair coarctation of the aorta; among them, narrow segment resection plus end-to-end anastomosis is one of the most widely used techniques in the neonatal population and in the group of younger infants. Unfortunately, many neonates have some degree of aortic arch hypoplasia, as well as extensive ductal tissue in the periductal aorta, and thus simple resection

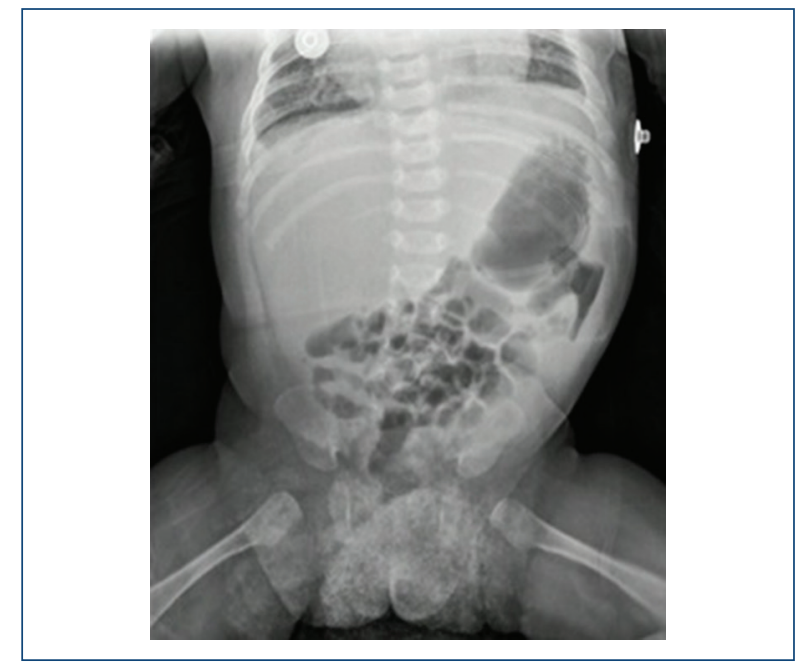

Figure 2. Gastric pneumatosis, upper third.

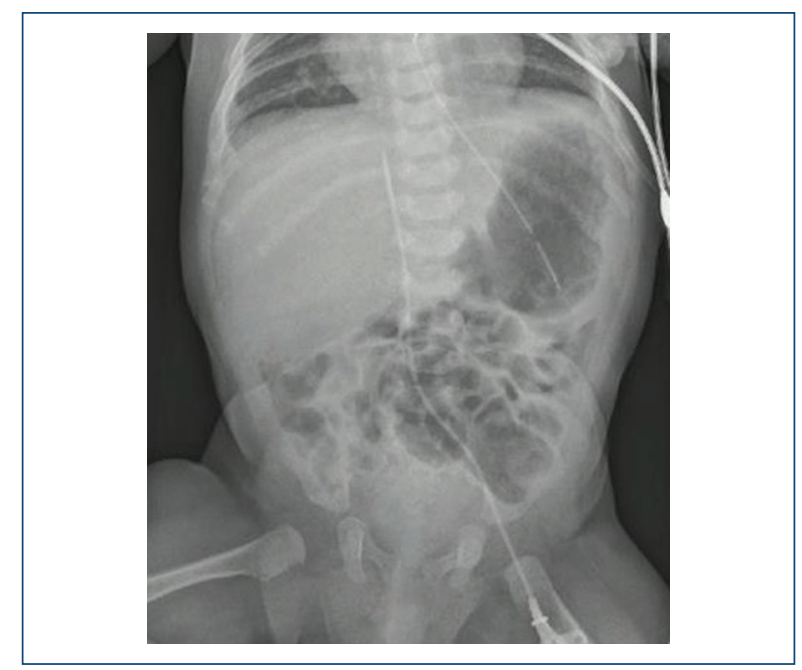

Figure 3. Residual pneumatosis.

and anastomosis is not always sufficient to ensure proper release of the coarctation site ${ }^{1}$, as in the described case, with major interventions under cardiorespiratory bypass being required. Similarly, despite the fact that deep hypothermic circulatory arrest theoretically protects intra-abdominal organs, this is a risk that is extensive to the entire splanchnic bed and, currently, no technique is available in children to protect this bed. Given that femoral vessels are too small and cannot be cannulated to provide protection and retrograde circulation, neither is it possible for the descending aorta to be cannulated and provide distal flow, as it has been done in the adult population. 
Among the surgical complications after this type of major cardiovascular procedures in children, non-occlusive mesenteric ischemia (NOMI) accounts for $1-4 \%$ of total, with a mortality rate of $60-100 \%{ }^{3}$. It was first described by Ende, in 1958, as the group of all forms of mesenteric ischemia without arterial occlusion. Although its exact pathophysiology is not very well understood, it is assumed that the causal mechanism is splanchnic flow extreme reduction or poor distribution, with mainly intestinal involvement, although other organs may also be affected ${ }^{5}$. Ischemia results in mucous layer integrity compromise, with bacterial translocation, bacteremia and multi-organ failure development ${ }^{6}$. Risk factors for the establishment of NOMI include: low cardiac output state, kidney failure with dialysis therapy requirement, liver failure, aortic regurgitation, use of vasoactive drugs that reduce splanchnic flow, major heart surgery, or aortic surgery requiring cardiopulmonary bypass, major abdominal surgery, and distant septic foci.

Regarding the mechanisms and mediators of this condition, the following have been established:

- Failure of the self-regulatory processes necessary to maintain intestinal perfusion pressure in the presence of sustained hypotension.

- Disproportionate vasoconstriction by the renin-angiotensin-aldosterone system and its derivatives, as a self-regulatory mechanism in the presence of intestinal hypoperfusion.

- Endothelin elevation in response to states of shock, release of catecholamines and angiotensin II, and coagulation cascade activation.

- Increased production of nitric oxide, which acts as a free radical and interferes with mitochondrial energy production.

- Use of alpha-adrenergic drugs, especially norepinephrine at doses $>0.1 \mu \mathrm{g} / \mathrm{kg}$ per minute.

In patients with marginal blood replacement in shock state and receiving vasopressors, in whom oxygen extraction has reached its maximum peak, any increase in metabolic demands on enterocytes for functions such as absorption, secretion and excretion is known to increase the risk of ischemia ${ }^{5,7}$.

Mild NOMI occurs without overt symptoms and can be resolved without sequelae, but severe NOMI is characterized by significant wall necrosis, perforation, peritonitis and death ${ }^{5}$. Clinical presentation typically includes abdominal distension, ileus, intestinal bleeding, fever, tachycardia and intestinal wall coloration changes. A high degree of suspicion and repeated clinical evaluations are required for early diagnosis to be established, which can be confirmed with abdominal X-rays showing loop dilation, pneumatosis intestinalis, hepatic portal venous gas and pneumoperitoneum in case of perforation ${ }^{3}$. Although ileum and distal jejunum are known to be the most affected structures ${ }^{6}$, the gastric cavity may be exceptionally compromised and its most relevant manifestation is the presence of gastric pneumatosis.

Gastric pneumatosis can be classified into three different conditions: benign gastric emphysema, phlegmonous gastritis and emphysematous gastritis. In benign gastric emphysema, increased intragastric pressure facilitates the entry of gas through areas where there is mucosal disruption or around the vascular sheath and perilymphatic spaces, as in case of gastric wall trauma or rupture of a pulmonary bulla. Radiologically, gas has a cystic, curvilinear/linear or bubbling aspect, patients usually do not look toxic, treatment is conservative and prognosis is good once the cause of intramural air is corrected. On the other hand, phlegmonous gastritis consists of gastric wall inflammation due to infection, but without intramural air ${ }^{4}$.

As for emphysematous gastritis, it is a rare disease described by Duo Vernoi in $1730^{2}$ and later by Fraenkel in $1889^{4}$, in which gastric wall inflammation is radiologically observed or presence of intramural gas is corroborated on intraoperative examination, together with systemic toxicity, explained by the formation of abscesses on the gastric wall, especially in the submucosa, with a tendency to drain into the gastric cavity, and gastric cellulitis development that can spread to the peritoneal cavity with secondary peritonitis production. Abdominal X-ray usually shows a bubbly-looking aspect inside the stomach wall (Fig. 1), similar to enterocolitis intestinal pneumatosis, with wall thickening and perigastric tissue density increase due to inflammatory and infectious changes. Sometimes, it is associated with pneumoperitoneum and pneumatosis of the portal vein and its intra-hepatic segmental lobular branches $^{8-10}$.

Since the first historical case reported by Fraenkel, a total of 68 cases have been recorded, out of which 59 correspond to patients older than 18 years of age ${ }^{4}$. Although it is most commonly associated with necrotizing enterocolitis and distal intestinal obstruction, it has also been reported in association with acid ingestion, erosive gastritis, intramural placement of a feeding tube, phytobezoars, gastric hematoma, ischemic events and major heart surgery, as the case herein described $8,11,12$. 
This condition usually occurs within the first week after the triggering event, although presentation time can be prolonged to up to 6 weeks later. Symptoms include epigastric abdominal pain, nausea, vomiting, diarrhea, in some cases melena and hematemesis, with signs of hemodynamic instability and leukocytosis; most these symptoms were present in our patient within the first 48 hours after the procedure and after trophic stimulus initiation with breast milk. Emphysematous gastritis pathognomonic sign is emesis of a necrotic mucosal clot caused by muscularis mucosae bacterial dissection. This was a characteristic finding in the infant, which led to hemodynamic decompensation secondary to the degree of anemia development.

The exact pathophysiology of the disease is not yet well elucidated. Normally, gastric mucosa protects the deep layers of the stomach through closed connections between mucosal cells, presence of acidic $\mathrm{pH}$ and blood flow replacement, which leads to adequate oxygenation and tissue repair ${ }^{9}$. Disruption of any of these barriers may explain the establishment of the disease. Possible etiologies for mucosal injury include necrosis by liquefaction secondary to alkalis ingestion, necrosis by coagulation due to acid ingestion, mucosal barrier disturbance in patients with ischemic events, previous gastrointestinal surgeries, chronic alcohol abuse and distant septic foci, with subsequent colonization and infection by different microorganisms. The bacteria most commonly involved in infection include E. coli, Streptococcus sp., Enterobacter sp., Pseudomonas aeruginosa, Clostridium welchi, staphylococci, Mucor $\mathrm{sp}$. and Candida sp, among others ${ }^{12}$. It is not clear how gas-producing bacteria penetrate the gastric wall, whether it is through mucosal ulceration or by hematogenous spread. However, tissue repair processes that depend on an adequate blood supply are compromised in cases of shock secondary to the release of pro-inflammatory cytokines, after procedures such as cardiopulmonary bypass, concomitant infectious conditions and intestinal vasculature hyper-contractile response secondary to the use of high doses of vasopressors, with all these characteristics being part of the clinical picture of the patient in question, which surely facilitated splanchnic circulation compromise and the establishment of a NOMI process with enphysematous gastritis as radiological and clinical manifestation. Finally, it should be remembered that intestinal ischemia processes can perpetuate systemic inflammatory response, which leads to a vicious circle that would explain a fatal outcome.
Although previous publications have shown that radiological findings along with adequate clinical suspicion are sufficient for diagnosis to be established, so far there is no general consensus on the preferred diagnostic modality. However, computed tomography has the advantage of its accessibility, good sensitivity and high specificity in gas detection, which makes of it the diagnostic method of choice ${ }^{12}$. With regard to NOMI, despite the possibility for poor perfusion to be detected by tomography, angiography remains the reference method for early diagnosis, as long as patient medical condition allows its performance. In addition to mesenteric flow direct visualization, the inserted catheter allows selective mesenteric intra-arterial infusion of vasodilator drugs, such as papaverine, nitroglycerin or glucagon in case of critical ischemia requiring organ reperfusion ${ }^{6,13}$.

Although there have been advances in medical and endoscopic management of this disease over the past 15 years $^{4}$, no study has performed a systematic analysis to determine survival predictors and identify trends regarding emphysematous gastritis endoscopic evaluation. Among current recommendations for the management of this pathology, monitoring of the patient in the intensive care unit is advised, trying to implement a treatment as conservative as possible, which should include fluid resuscitation, vasoactive and ventilatory support in case of shock, broad-spectrum antibiotic therapy, transfusion support and acid production suppression with a proton pump inhibitor. Surgery is not indicated unless there is evidence of perforation or necrosis, or if conservative management has failed, with mortality reported in some series to be higher than $60 \% 3,4,10$.

Prognosis is favorable if diagnosis has been early established, as well as if antibiotic therapy is early implemented, accompanied by supportive management ${ }^{14,15}$. If evolution is good, healing will be produced with connective tissue hyperplasia and residual fibrosis or chronic gastritis, which due to its appearance resembles Brinton's linitis plastica ${ }^{10}$. Of the patients who survive, approximately $20-25 \%$ develop gastric stenosis requiring dilatation ${ }^{4}$.

\section{Conclusions}

Splanchnic hypoperfusion after major heart surgery, especially of aortic bed, remains the silent enemy, especially in newborns and infants. Consequently, a torpid hemodynamic evolution after an optimal surgical result forces to think about hypoperfusion of other 
organs, among which the gastrointestinal tract is one of those at highest risk. Despite its rich irrigation, the gastric cavity can be compromised, with this involvement being expressed as emphysematous gastritis and, in turn, as a NOMI manifestation. High clinical suspicion is necessary in order for early medical intervention to be implemented, and thus avoid the possibility of complications and the need for surgical intervention, which clearly worsen patient prognosis.

\section{Funding}

This research has not received any specific funding from public, commercial or non-profit sector agencies.

\section{Conflicts of interest}

The authors of this article declare that they have no conflicts of interest.

\section{Ethical disclosures}

Protection of human and animal subjects. The authors declare that no experiments have been performed on humans or animals for this research.

Confidentiality of data. The authors declare that they have followed the protocols of their work center on the publication of patient data.

Right to privacy and informed consent. The authors have obtained informed consent from the patients and/or subjects referred to in the article. This document is in the possession of the corresponding author.

\section{References}

1. Hastings L, Nichols D. Coarctation of the aorta and interrupted aortic arch. En: Nichols D, Ungerleider R, Spevak P, Greeley W, Cameron D, Lappe D, et al., editores. Critical heart disease in infants and childrens. $2^{\text {nd }}$ ed. Philadelphia: Mosby Elsevier; 2006. p. 699-713.

2. Gil M, Balanzar J, Victoria G, Miguel M, López H, Ramírez A, et al. Diagnóstico de neumatosis gástrica en pacientes pediátricos. Reporte de series de casos. Acta Pediatr Mex. 2018;39:179-84.

3. Valencia M, Cassalett G. Sistema gastrointestinal y nutrición. En: Cassalett $\mathrm{G}$, editor. Manual de cuidado intensivo cardiovascular pediátrico. Bogotá: Distribuna; 2016. p. 155-67.

4. Watson A, Bul V, Staudacher J, Carroll R, Yazici C. The predictors of mortality and secuelar changes in management strategies in emphysematous gastritis. Clin Res Hepatol Gastroenterol. 2017;41:e1-7.

5. Al-Diery H, Phillips A, Evennett N, Pandanaboyana S, Gilham M, Windsor J. The pathogenesis of nonocclusive mesenteric ischemia: implications for research and clinical practice. J Intens Care Med. 2019;34:771-81.

6. Groesdonk H, Klingele M, Schlempp S, Bomberg H, Schmied W Psych D, et al. Risk factors for nonocclusive mesenteric ischemia after elective cardiac surgery J Thorac Cardiovasc Surg. 2013;145:1603-10.

7. Sato $\mathrm{H}$, Nakamura M, Uzuka T, Kondo M. Detection of patients at high risk for nonocclusive mesenteric ischemia after cardiovascular surgery. J Cardiothorac Surg. 2018;13:115.

8. Travadi J, Patole S, Simmer K. Gastric pneumatosis in neonates: revisited. J Paediatr Child Health. 2003;39:560-2.

9. Moosvi A, Saravolatz L, Wong D, Simms S. Emphysematous gastritis: case report and review. Rev Infect Dis. 1990;12:848-55.

10. Zamora M, Labarta L, Escos J, Cambra P, Vernal V, Seron C. Gastritis enfisematosa, eficacia del tratamiento con antibioterapia precoz. Gastroenterol Hepatol. 2016;39:393-402.

11. Murnan S, Miller J, Kuhn A. Gastric emphysema. A cannot-miss emergency medicine diagnosis. Pediatr Emerg Care. 2019;35:e152-3.

12. Cappa G, Silva R, Lisandrello N, Fadlala J. Gastritis enfisematosa como causa infrecuente de abdomen agudo. Rev Med Rosario. 2014; 80:129-34.

13. Björck M, Wanhainen A. Nonocclusive mesenteric hypoperfusion syndromes: recognition and treatment. Semin Vasc Surg. 2010;23:54-64.

14. Lee S, Kim G, Kang D, Kim T, Song G, Kim S. Gastro-intestinal emphysematous gastritis. J Gastroenterol Hepatol. 2007;22:2036-9.

15. Yalamanchili $M$, Cady W. Emphysematous gastritis in a hemodialysis patient. South Med J. 2003;96:84-8 